\title{
Quaderni
}

QUADERNI Communication, technologies, pouvoir

76 | Automne 2011

Les promesses de la biodiversité

\section{Engineering the Planet: the issue of biodiversity in the framework of climate manipulation and climate governance}

\section{Chunglin Kwa and Mieke van Hemert}

\section{(2) OpenEdition \\ 1 Journals}

\section{Electronic version}

URL: http://journals.openedition.org/quaderni/145

DOI: 10.4000 /quaderni.145

ISSN: 2105-2956

Publisher

Les éditions de la Maison des sciences de l'Homme

\section{Printed version}

Date of publication: 1 September 2011

Number of pages: $79-89$

\section{Electronic reference}

Chunglin Kwa and Mieke van Hemert, « Engineering the Planet: the issue of biodiversity in the framework of climate manipulation and climate governance », Quaderni [Online], 76 | Automne 2011, Online since 01 September 2014, connection on 01 May 2019. URL : http://journals.openedition.org/ quaderni/145; DOI : 10.4000/quaderni.145 


\section{$D$ ossier}

\section{engineering the Planet : \\ the issue of biodiversity in the framework of climate manipulation and climate} governance

\author{
Chunglin \\ Kwa
}

University of Amsterdam

\section{Mieke van Hemert}

Vrije Universiteit Amsterdam
Project Stormfury was among the most prominent weather modification programs of the 20th Century. Running from 1962 to 1983, it had a brief moment of glory in 1969. In that year, Hurricane Debbie was "seeded" five times : the clouds were sprinkled with silver iodide crystals released from air planes. The experiments seemingly succeeded in reducing wind speeds, and moreover, the good results were confirmed by a computer simulation model developed at Stormfury, at the time one of the most advanced of its kind. But in 1983, the developer of the model, Stanley Rosenthal, conceded that predicting the outcome of seeding experiments was theoretically not possible. In retrospect, he deemed the strange behaviour of the hurricane Debbie as the result of its natural evolution. ${ }^{1}$

Very many weather modification projects were in operation during the period that Stormfury ran, ranging from very big to very small, with projects benefitting from US government support and large scale funding from the NSF to small commercial projects. Stormfury itself received support from the Navy. It was, among other things, a typical Cold War project. At the other end of the scale, commercial weather modification dealt with the complexities of the atmosphere and uncertainties about the effects of intervention, too. Usually, cloud seeding firms operated in a straightforward fashion, on a "no cure, no pay" basis. Only if there was rain after the cloud seeding operation, the drought stricken farmer would pay. But there were cases where instead of beneficial rain a devastating flood was produced. When taken to court, however, the cloud seeders would invariably make the case that the atmosphere was far too complex to establish a 
relationship between the seeding and the disaster. Usually, their argument was accepted.

With these experiences in mind, it seems astonishing that weather modification has returned on a much grander scale : climate manipulation, usually called geoengineering. Since around 2005 , several dozens of scientific teams are investigating a variety of geoengineering techniques and the US National Academy and the UK Royal Society have issued reports in which they advocate research into geoengineering. ${ }^{2}$ Paul Crutzen, the renowned climate scientist and Nobel Prize winner, advocated that humankind should get prepared to blast enormous quantities of sulphate particles into the stratosphere. ${ }^{3}$ This would produce a global cooling effect, if urgently needed, similar to the (temporary) cooling of large vulcano eruptions. If this seems science fiction and at any rate far away in the future, other forms of geoengineering are closer to application in the real world. A series of smaller scale experiments involving so-called ocean fertilization have already been carried out. Adding iron or another nutrient to the ocean would cause algal bloom, thereby taking up carbondioxide from the atmosphere. The Convention on Biological Diversity has taken steps toward a ban on large scale open ocean experiments of this kind, for reasons to be discussed below.

The reason to engage in geoengineering seems simple : climate change is happening and the world does not succeed in curbing carbondioxide emissions. Quite the contrary in fact. Perhaps in a few decades from now, the world will experience an average rise of temperature of more than $2^{\circ} \mathrm{C}$, a figure which is generally acknowledged to cause important and irreversible dangers. Something must be done. But why get involved in geoengineering ? Is there any reason to suppose that the lessons from Stormfury will not apply to climate manipulation? Compared to 1983 , we have hugely more data on the atmosphere and hugely more computer capacity. But the understanding of the complexity of large natural systems has hardly progressed in the same manner. Insofar it has, the study of complexity has given us much more insight in the inherently unstable nature of large natural systems and of their "jumpiness", their capacity to react very strongly on a comparatively tiny change in one of the variables in its environment. In an optimistic note, climate scientists note that the global climate responds more linearly to changes of atmospheric variables than the (local) weather. But nobody lives in the global climate. Global climatic change translates very differently to different regional climates, in a non-linear and hence unpredictable fashion.

In its 2009 Report, the Royal Society has acknowledged considerations of this kind and has nevertheless taken the stand that geoengineering should be taken very seriously. The Report is a landmark report on several accounts. It is a systematic and critical evaluation of all the geoengineering proposals that have been made in the past decade. It charts the uncertainties around the various interventions in the climate, to several of which it takes a very critical stance. It addresses the 'governance' issues around geoengineering, i.e. the social and political conditions for any larger scale intervention in nature in a more sophisticated way than several predecessors, and it invited a panel of ethicists to comment on geoengineering issues. But one remark towers 
over and above all kinds of cautionary stands the Royal Society is taking : "Why should appropriate geoengineering options not be added to the portfolio of options of dealing with climate change?" It also has a key recommendation : “.... Solar Radiation Management methods may provide a potentially useful short-term backup to mitigation in case rapid reductions in global temperatures are needed." The Report also says that "...Geoengineering is likely to be technically feasible, and could substantially reduce the costs and risks of climate change." It is not, therefore, an option of last resort. ${ }^{4}$ With the Report, the Royal Society is the first public institution of high authority to throw its weight behind climate manipulation. In fairness to the RS, it should be pointed out that it does not advocate geoengineering as an alternative to greenhouse gas reduction (in contrast to, for instance, Newt Gingrich, a Republican candidate to the US Presidency and former climate sceptic, who sees geoengineering as a welcome alternative to the curbing of carbon dioxide emissions). But the RS considerably raised the stature of geoengineering, which was considered by many as close to science fiction.

\section{The geoengineering techniques evaluated by the Royal Society}

Solar Radiation Management (SRM) is one of the two categories in which all geoengineering techniques can be divided, according to the RS's overview, the other being Carbon Dioxide Removal (CDR). The latter approaches global warming abatement by its root cause. If this makes it by far the most preferred, CDR has two disadvantages : it will take considerable time to sort out effect, and while most CDR techniques seem to be technically feasible in the short run, the necessary scaling-up of the techniques will pose many technical and governance problems. One CDR technique is uncontested and already agreed upon internationally : afforestation, reforestation and avoidance of deforestation. But there are several more, all in an embryonic stage.

The furthest developed, as already mentioned, is ocean fertilization. Risks of unanticipated environmental effects are evaluated as high in the RS Report. Ocean fertilization is a form of intentionally changing marine ecosystems, with all kinds of known and unknown dangers to biodiversity, while poisoning of remote areas may be among the possible outcomes, due to the transportation by ocean currents of the dying algae. Not only is the efficiency of ocean fertilization probably low, but it would also not be easily verifiable given the complexity of the large marine ecosystems. "It is hard to tell whether [the fertilization mechanisms] are working or not". On top of that, the RS Report notes, the technique is very risky and "there are likely to be unintended and probably deleterious ecological consequences." Despite these judgments, the RS Report suggests that a moratorium is not a good idea, as it would hamper research. ${ }^{6}$

The International Oceanographic Commission (IOC), an organization which forms part of UNESCO, likewise does not endorse ocean fertilization. A report commissioned by the IOC states that "we rarely understand the factors and mechanisms that cause large-scale, natural regime shifts within marine ecosystems". ${ }^{7}$ But ocean fertilization does have partisans within the scientific community and a California-based company, Climos, expresses interest in develop- 
ing ocean fertilization commercially. (Its business model is based on expected financial compensation for earning carbon credits in the regulatory environmental markets, on the assumption that society would be willing to allow ocean fertilization). ${ }^{8}$ Rock star Neil Young is also enthusiastic about ocean fertilization and he offered the yacht he owns in Hawaii for carrying out fertilization experiments. The proposals have met with sharp criticism in the scientific literature, in which it is pointed out that commercial parties might be difficult to restrain once they get in for profit. ${ }^{9}$

CDR methods of which the risks are estimated as "medium" are biochar (charcoal) production and other forms of biomass sequestration. The RS Report is rather reluctant about these techniques. While they may yield significant small scale contributions, the RS fears that they might become competitors to food crops, in a manner similar to biofuels. ${ }^{10}$

One new CDR technique does get an approval from the RS : "enhanced weathering" (on land, not in the ocean). The idea is based on the observation that the weathering of rocks involves the capture of carbondioxide. Normally, however, this is an extremely slow process taking aeons, since only the surface of rocks is exposed to the air. "Enhancing" the weathering process would involve mining and grounding of rocks and spreading the resultant powdered materials over fields, where it would have a fertilizing effect. According to the RS Report, "Enhanced weathering is expected to be reasonably effective", and it is placed in the low risk category with respect to unintended consequences. The foreseeable environmental impact would be similar to conven- tional coal mining and cement production. ${ }^{11}$ The RS Report does not give estimates of the scale which would be needed for this operation, other than noting that it would be "large", and "likely to damage the environment locally over large areas". When we also take into consideration that the technical problems of weathering are far from solved (one of them being that the chemical reactions involved in weathering produce heat), the overall judgment of the RS Report seems much too positive.

The various Solar Radiation Management (SRM) techniques, the second major class of climate manipulation methods, should have stayed in the science fiction category. Take the idea of installing in space, 1.5 million kilometers from the Earth where the gravitational fields of the Sun and the Earth are in balance, a layer of reflecting disks fabricated in space from near-Earth asteroids. Or "hanging" there a superfine mesh of aluminium threads. The RS Report does not want to "dismiss them from future consideration". ${ }^{12}$ Reducing solar radiation does not attack global warming in its root cause. Compared to the CDR techniques, their main advantage is that once put into place they would work fast, on a timescale of years instead of decades. But they would require development time, which the RS estimates at several decades. Given the nature of these techniques as totally last-resort, when-all-else-fails, who is going to initiate them and pay for their development? Edward Teller is the originator of several SRM ideas. At one point, Teller was able to convince President Reagan to embark on the Strategic Defence Initiative (Star Wars). But he died in 2003. Is there a scientist to take his place?

One candidate is Paul Crutzen. As mentioned, 
in 2006 Crutzen adopted and developed one of Teller's ideas : blasting aerosols in the stratosphere. It received much attention. The attractiveness of the stratospheric aerosols proposal comes from the analogy with volcanic eruptions. Mount Pinatubo erupted in 1991. In the two following years, there was a marked cooling effect, globally. The artificial injections would simply mimic a natural occurrence. The aerosol method seems to have three advantages : the mechanism is simple compared to, for instance, interventions in marine ecosystems; delivery in the upper layers of the atmosphere requires just airplanes or rockets; costs are estimated as tens of billions of dollars. The RS concludes that of all the SRM methods "stratospheric aerosols appear to be the most promising". Even though it notes that significant further research is needed on adverse effects, this judgment is, again, surprisingly positive. ${ }^{13}$ As noted in the RS report, the Pinatubo eruption caused a reduction of the ozone layer, and this is also one of the potential negative side effects of stratospheric aerosols. Not noted in the RS report, however, is the fate of the aerosol particles which would come down and pollute the environment. Possible differences in regional impact are noted, but are not emphasized at all. They may, however, turn out to be dramatic : the Asian Monsoon might become disrupted, with catastrophic consequences for agriculture in the region. Wide disagreements between Northern and Southern countries on the application of the technique can be expected. ${ }^{14}$

Evaluating the Royal Society evaluating the various geoengineering techniques, we find that the Report does contain a number of cautionary observations but omits quite a few that it could and should have discussed. Moreover, the Report displays a "can do" mentality, even in science fiction cases, which apparently the humanities scholars on the working group have not been able to contain within proper bounds. This raises a question : to what extent does the Report voices the opinion of the scientific community on global warming abatement? Is the Royal Society "speaking in the name of science" ? According to historian James Fleming it does not in this case. A survey of recent pronunciations on the subject makes this clear. And neither, according to Fleming, is there much public support for large-scale interventions in the Earth' natural systems. ${ }^{15} \mathrm{~A}$ year prior to the release of the Report, the Royal Society published a special issue of its Philosophical Transactions which, on issues such as ocean fertilization, was far more uncritically supportive than the Report. Some of the authors in Transactions, such as Ken Caldeira, a known protagonist of SRM, and Brian Launder, came to serve as members of the RS working group. On their topics, the Report spoke favourably. ${ }^{16}$ The Royal Society may have accidently brought together a group of partisan scientists. Yet, we cannot rule out the possibility that Crutzen did rally an important number of scientists around the idea of SRM. This, at least, is the impression of Steve Rayner, the STS scholar who served on the Royal Society's working group which prepared the Report. ${ }^{17}$

\section{The governance of geoengineering the cli- mate : Will principles suffice?}

To the Royal Society Report's credit, it should be said that it devoted a large section to issues of governance of geoengineering. What are the 
social and political conditions for engaging with it ? Do we have opt-out possibilities once we decided to go for it? Do regulatory gaps exist ? Is the public and is civil society sufficiently engaged? These are among the important questions that the Report raises.

Yet the RS Report has a reassuring tone : issues and concerns must be raised, but with proper governance frameworks, governments and intergovernmental bodies will be able to make reasonable and responsible decisions, informed by public dialogue and underpinned by the latest available scientific evidence. The "technology control dilemma" is referred to as a central problem for geoengineering as an emerging technology. Too little is known about the consequences of geoengineering, which precludes anticipating and controlling undesirable side-effects.

An answer to this dilemma has been "risk assessment". This is an insufficient answer, according to the RS Report, since indeterminacy and ignorance prevail and unintended consequences may be unavoidable. The "precautionary principle" emerged as a way to deal with decisionmaking under conditions of ignorance. The Report notes that a moratorium is a possible answer, and the Convention on Biological Diversity actually took steps toward a moratorium, first on ocean fertilization and, with the Conference Of Parties $10 \mathrm{X} / 33$ decision, on any geoengineering activity which has effects on biodiversity. The 2008 moratorium pronounced that no ocean fertilization should take place before risks had been assessed and proper global control and regulation were in place. An exception was made for small-scale scientific studies within coastal waters. Com- mercial ocean fertilization was ruled out. ${ }^{18}$ In January 2009, one ocean fertilization experiment was temporarily suspended, but after environmental assessments were made the experiment was allowed after all. Conducted by the German Alfred Wegener Institute in the Southern Ocean, controversy over the experiment had arisen about its classification as a 'small scale scientific experiment'. ${ }^{19}$ According to its opponents, it classified as geo-engineering. It was at any rate the largest experiment since ocean fertilization experiments started in 1993 : 10 tonnes of iron sulfate were released on a patch of $300 \mathrm{~km} 2$. Probably in the context of the controversy over this experiment, the RS Report finds that a moratorium is not a good idea, because it would inhibit research. It would be preferable to build a responsible international research community.

The precautionary principle is given credit as a guiding principle, but it is noted that this principle is interpreted in widely varying ways. In the end, it is up to societal actors to negotiate what precaution means, and it will be a matter of weighing concerns about the consequences of climate change on the one hand and concerns about side-effects of geoengineering techniques on the other.

In connection with the control dilemma, problems of irreversibility are discussed, too. There is reason to fear that, once certain steps have been taken, it will be difficult to retreat. These problems are to be dealt with by assessing the degree of technical reversibility of the different options and by paying attention to developing social and economic irreversibilities caused by investments and vested interests. 
Despite a number of reservations, Rayner is an advocate of "upstream" societal engagement with emerging technologies and unorthodox ways of climate change abatement. After the completion of the RS Report, he went on to with elaborating draft principles for geoengineering governance. The five 'Oxford principles' on geoengineering as the memorandum to the House of Commons came to be called, are the fruit of labour of a team headed by Rayner, with four other scholars with backgrounds in international laws, ethics, risk management and geoengineering. ${ }^{20}$ Now endorsed by the UK parliament, British researchers are being requested to adopt the principles as their code of conduct.

Will the world be a better place now ? The Oxford principles formulate rules, in very general terms, on public engagement, transparency, risk assessment and robust governance frameworks. Terms as "informed consent" have a legal ring taken from internationally binding trading agreements on potentially harmful products ${ }^{21}$, while "public good" seems too weak a concept when commercial parties are allowed to earn carbon points in the context of international agreements. An underlying theory of democratic governance of technology can be vaguely discerned : science and technology are a public good, the risks and benefits of which should be assessed and regulated in an open and independent way with which the public should engage "upstream", paying attention to a wide range of risks, including technical, environmental, social and economic, so as to mitigate undesirable irreversibilities. In a more recent contribution, Rayner invokes a "geo-engineering paradox": the technology that seems to be nearest to maturity (aerosol seeding) is the most difficult to implement from a social and political perspective, and vice versa.

The RS Report's discussion of governance was the first governance framework for geoengineering, though not for related issues. The moratorium on ocean fertilization was agreed on in 2008, and the London Convention 1972 and London Protocol 1996 to which it referred served as a framework to prevent marine pollution through dumping of waste. The Science and Implementation Plan of the Earth System Governance Project of the International Human Dimensions Programme on Global Environmental Change (IHDP-GEC), which was finished in 2009 after five years of consultations, does not devote a single word to geoengineering. ${ }^{22}$ That said, the plan offers ample space for addressing issues of geoengineering governance. It has four cross-cutting research themes : power, knowledge, norms and scale. It put problems of justice, legitimacy, and accountability on the agenda; the plan also builds on Science and Technology Studies (STS) research. ${ }^{23}$ Questions around "the intersection of power and knowledge and how this shapes the way Earth system challenges are framed and potential policy response agendas set" seem as pertinent for geoengineering governance to ask as for other Earth governance issues. ${ }^{24}$

This is a research agenda to which Rayner has amply contributed. We should acknowledge that power relations are fully at work in the framing of problems and solutions and that rhetorics of principles and codes of conduct say little about the sociomaterial practices on the ground (or in the ocean, or the sky for that matter). Rayner cannot be content with principles. Principles come 
with idealistic accounts of democracy. Building on pragmatist accounts of democracy, Noortje Marres has argued that democratic politics and the governance of risk involves articulation of "issues" by societal actors, rather than principles and procedures for public participation in decisionmaking. ${ }^{25}$ When ignorance prevails, existing institutions are unable to resolve issues, partly because it is unclear who will be affected by the consequences of decisions and in what ways. Under those circumstances, it is up to citizens to engage themselves with an issue beyond the procedural settings of decisionmaking, and articulate its many sides. As issue articulation is not geared towards consensual decisonmaking, it renders explicit irreconcilable framings and ways of engaging with the world, which may amount to incommensurable worldviews and worldmakings. These antagonisms are a valuable and inevitable aspect of issues going "public".

Issue articulation, then, is a dynamic process. It may undergo shifts, sometimes radical shifts, through the way problems are framed by the various participants, and draw in new participants and institutions. One example is the public debate on genetically modified crops in France. ${ }^{26}$ In 1986, GM crop research was framed around the notion of "innovation". Research funding for innovation in genetic modification was made available, providing ample space for the setting up of (laboratory) experiments. A few years later, EU regulation made risk assessment mandatory. A distinction between experimental and commercial releases became accepted in France (at the EU level a proposed moratorium was rejected by one vote). This distinction would determine a shift in the conceptualization of "experiments".
The expert committee advising the French government argued that contained field experiments were needed to find out about possible risks. Around 1993, experts began to argue that risks could only be accurately evaluated in largescale field trials. These were allowed as a new category under the condition of being monitored. In 1996, population biologists - who saw expert committees dominated by molecular biologists called for a moratorium on commercial releases, while environmentalists continued to emphasize "risks". A few years after, farmers organizations and activists started to destroy field trials, justifying the demolition as "a legitimate act of precaution". In their view, the field trials served the interests of the agro-food industry. Further development of GMOs, they argued, would bring increased monopolization and commodification of seeds. In court cases, judges agreed that destruction of field trials could be legitimate and not illegal.

In the case of geoengineering, articulation of issues outside scientific circles has started relatively recently. Public debate became pronounced only after the Royal Society issued its Report. Some of the dynamics of articulation of individual geoengineering techniques like ocean iron fertilization are remarkably similar to those of the GM case discussed above. There is a push for scaling up experiments by scientific-commercial consortia while the distinction between scientific experiments and deployment has been called into question. ${ }^{27}$ The dominant risk assessment framing is being challenged. Given this context, the central message of the RS Society Report, that research on geoengineering should be promoted, 
is not as innocent as it seems.

The lesson of project Stormfury and other weather modification projects in the 1960s and 1970 s is that little can be taken for granted about knowledge claims, interpretive flexibility of principles and the strategies of private companies. There is certainly no reason to ask fewer questions about Earth politics. When oceanographers note that "[d] espite these uncertainties in the science, private organizations are making plans to conduct larger-scale iron releases to generate carbon offsets" and "field studies on larger spatial and longer timescales" as part of targeted reasearch programmes "to reduce uncertainties", thereby challenging the ban on ocean fertilization, it is time to question the practices going on under the label of geoengineering governance. ${ }^{28}$

\section{Acknowledgments}

We thank Céline Granjou, Isabelle Mauz and Arthur Petersen for their comments on an earlier version of this article.
$\mathrm{N} \cdot \mathrm{O} \cdot \mathrm{T} \cdot \mathrm{E} \cdot \mathrm{S}$

1. Chunglin Kwa, "The Rise and Fall of Weather Modification : Changes in American Attitudes Toward Technology, Nature and Society", in : Clark A. Miller and Paul N. Edwards, Changing the Atmosphere: Expert Knowledge and Environmental Governance, Cambridge, Ma., The MIT Press, 2001, pp. 135-165.

2. The Royal Society, Geoengineering the Climate : Science, governance and uncertainty, London, Royal Society, September 2009.

3. Paul Crutzen, "Albedo Enhancement by Stratospheric Sulfur Injections : A Contributin to Solve a Policy Dilemma", Climatic Change 77 (2006), pp. 211-220.

4. Royal Society, Geoengineering, p. 45, xi, 57.

5. In 2009, the CBD evaluated the effects of ocean iron fertilization on biodiversity on the basis of data collected in the 13 open ocean experiments conducted since 1993. The effects of iron fertilization appeared to be very variable, but in five experiments diatoms came to dominate. In the largest experiment, conducted in 2009 , diatoms did not proliferate because of a lack of silica, as a result of natural blooms before the experiment. The algal community was quickly eaten by an amphipod species (p. 36). The variability in biodiversity effects observed during the experiments thus seems large, while biodiversity effects in deeper waters and the seabed were not monitored (p. 46). See : Secretariat of the Convention on Biological Diversity Scientific Synthesis of the Impacts of Ocean Fertilization on Marine Biodiversity. Montreal, Technical Series No. 45, 2009, 53 pages.

6. Royal Society, Geoengineering, pp. 17-19.

7. D.W.R. Wallace et al, Ocean Fertilization : A scientific summary for policy makers, Paris, IOC/ UNESCO, 2010.

8. See www.climos.com, last accessed on June 7, 
2011; another company with ocean fertilization plans, Planktos, in San Francisco, went bankrupt in 2008 but has apparently gone back into bussines.

9. John J. Cullen and Philip W. Boyd, Predicting and verifying the intended and unintended consequences of large-scale ocean iron fertilization, Marine Ecology Progress Series 364 (2008), 295-301; see also : Stefan Helmreich, Alien Ocean : Anthopological Voyages in the Microbial Seas, Berkeley, University of California Press, 2009, pp. 132-133.

10. Royal Society, Geoengineering, p. 12.

11. Ibid, pp. 14, 20.

12. Ibid, p. 33.

13. Ibid, pp. 32, 36.

14. ETC Group, Geopiracy: The case against geoengineering, Manila, 2010.

15. James R. Fleming, Fixing the Sky: The checkered history weather and climate control, New York, Columbia University Press, 2010, p. 255.

16. Brian Launder and J. Michael T. Thompson (eds.), "Geoscale Engineering to Avert Dangerous Climate Change", special issue Philosophical Transactions of the Royal Society A 366 (2008), quoted in Fleming, Fixing, 2010, p. 258-261.

17. Steve Rayner, "Climate Geoengineering Governance", forthcoming in : Jahrbuch Ökologie, 2011.

18. http ://www.cbd.int/decision/cop/ ?id=11659.

19. Aaron L. Strong, John J. Cullen and Sallie W. Chisholm "Ocean Fertilization. Science, Policy and Commerce", Oceanography 22 (2009), p. 246

20. Steve Rayner et al. Memorandum on draft principles for the conduct of geoengineering research. House of Commons Science and Technology Committee enquiry into The Regulation of Geoengineering, 2009. The Oxford Principles are : Geoengineering to be regulated as a public good; Public participation in decision making; Disclosure of geoengineering research and open publication of results; Independent assessments of impacts; Governance arrangements to be clear before deployment.

21. Aarti Gupta, "Governing Trade in Genetically Modified Organisms : The Cartagena Protocol on Biosafety", Environment : Science and Policy for Sustainable Development 42 (2000), pp. 23-33.

22. Frank Biermann et al., Earth System Governance : People, Places and the Planet. Science and Implementation Plan of the Earth System Governance Project. Earth System Governance Report 1, IHDP Report 20, Bonn : IHDP, 2009.

23. Notably on Sheila Jasanoff's work, including Sheila Jasanoff and Marybeth Long Martello (eds), Earthly Politics : Local and Global in Environmental Governance. Cambridge, MA, MIT Press, 2004, and also on Bruno Latour, Brian Wynne and on earlier work by Steve Rayner.

24. Biermann et al., Earth System Governance, p. 71. 25. Noortje Marres "The Issues Deserve More Credit : Pragmatist Contributions to the Study of Public Involvement in Controversy", Social Studies of Science 37 (2007), pp. 759-780.

26. Christophe Bonneuil, Pierre-Benoit Joly and Claire Marris, "Disentrenching experiment. The construction of GM-crop field trials as a social problem in France" in : Science, Technology and Human Values 33 (2008), pp. 201-229.

27. Aaron L. Strong, John J. Cullen and Sallie W. Chisholm "Ocean Fertilization. Science, Policy and Commerce" in : Oceanography 22/3, 2009, pp. 236-261. See also Wolfgang Krohn and Johannes Weyer, "Society as a laboratory : the social risks of experimental research", Science and Public Policy 21 (1994), pp. 173-183.

28. See Ken O. Buesseler et al., "Iron ocean fertilization : moving forward in a sea of uncertainty", Science, vol. 319, 2008, p. 162. 


\section{$\mathrm{R} \cdot \dot{E} \cdot \mathrm{S} \cdot \mathrm{U} \cdot \mathrm{M} \cdot \dot{\mathrm{E}}$}

Le rapport de la Royal Society intitulé Geoengineering the Climate, publié en 2009, marque une étape cruciale à divers titres. Cette contribution propose une évaluation critique de différentes techniques de geoengineering que la Royal Society considère, dans ce rapport, comme susceptibles de contribuer à la réduction du réchauffement global. Elles peuvent être regroupées en deux grandes catégories : les techniques de gestion des radiations solaire, et celles de retrait de dioxyde de carbone. La Royal Society propose également un cadre de gouvernance pour guider la recherche future ainsi que l'application des techniques de geoengineering. Basés sur ce cadre, des principes dits « Principes d'Oxford » ont été formulés. Ils articulent des règles en des termes très généraux autour de l'engagement public, la transparence, l'évaluation des risques et les cadres d'une gouvernance robuste du geoengineering. Dans cette contribution, nous défendons l'idée que ces principes ne sont pas suffisants pour aborder les initiatives actuelles dans le domaine du geoengineering. Les firmes privées encouragent les études sur le terrain à de larges échelles de temps et d'espace, qui battent en brèche le moratoire proposé par la Convention sur la Diversité Biologique. Maintenant que la distinction entre expérimentation scientifique et déploiement grandeur nature est mise en question, il convient de réexaminer les pratiques regroupées sous le label de gouvernance du geoengineering et d'appeler à un large débat public sur ces questions scientifiques.

\footnotetext{
Abstract

The Royal Society report on Geoengineering the Climate, published in 2009, is a landmark report on several accounts. This article assesses critically a number of the geoengineering techniques, in the
}

broad categories of Solar Radiation Management and Carbon Dioxide Removal, which the Royal Society considers as candidate technologies for global warming abatement. The Royal Society also proposed a governance framework to guide future research on and application of geoengineering techniques. Building on this framework, the so-called Oxford Principles were derived. The Oxford Principles formulate rules, in very general terms, on public engagement, transparency, risk assessment and robust governance frameworks with respect to geoengineering. In this article, it is argued that principles are not adequate to deal with ongoing initiatives in the field of geoengineering. Private organizations are pushing for field studies on larger spatial and longer timescales and thereby challenge a moratorium proposed by the Convention on Biological Diversity. Now that the distinction between scientific experiments and deployment has been called into question, the practices going on under the label of geoengineering governance need to be reexamined and recognized as broad public-scientific issues.

Mots-clefs : geoengineering, évaluation des risques, gouvernance, expérimentation scientifique, débat public. 
